\title{
Decreased vitamin B12 availability induces ER stress through impaired SIRT1-deacetylation of HSF1
}

\author{
R Ghemrawi ${ }^{1}$, S Pooya ${ }^{1}$, S Lorentz ${ }^{1}$, G Gauchotte ${ }^{1}$, C Arnold ${ }^{1}$, J-L Gueant ${ }^{\star^{1,2}}$ and S-F Battaglia-Hsu ${ }^{\star 1,2}$
}

Vitamin B12 (cobalamin) is a key determinant of S-adenosyl methionine (SAM)-dependent epigenomic cellular regulations related to methylation/acetylation and its deficiency produces neurodegenerative disorders by elusive mechanisms. Sirtuin 1 deacetylase (SIRT1) triggers cell response to nutritional stress through endoplasmic reticulum (ER) stress. Recently, we have established a N1E115 dopaminergic cell model by stable expression of a transcobalamin-oleosin chimera (TO), which impairs cellular availability of vitamin B12, decreases methionine synthase activity and SAM level, and reduces cell proliferation. In contrast, oleosin-transcobalamin chimera (OT) does not modify the phenotype of transfected cells. Presently, the impaired cellular availability of vitamin B12 in TO cells activated irreversible ER stress pathways, with increased P-elF-2 $\alpha$, P-PERK, P-IRE1 $\alpha$, ATF6, ATF4, decreased chaperon proteins and increased pro-apoptotic markers, CHOP and cleaved caspase 3 , through reduced SIRT1 expression and consequently greater acetylation of heat-shock factor protein 1 (HSF1). Adding either B12, SIRT1, or HSF1 activators as well as overexpressing SIRT1 or HSF1 dramatically reduced the activation of ER stress pathways in TO cells. Conversely, impairing SIRT1 and HSF1 by siRNA, expressing a dominant negative form of HSF1, or adding a SIRT1 inhibitor led to B12-dependent ER stress in OT cells. Addition of B12 abolished the activation of stress transducers and apoptosis, and increased the expression of protein chaperons in OT cells subjected to thapsigargin, a strong ER stress stimulator. AdoX, an inhibitor of methyltransferase activities, produced similar effects than decreased B12 availability on SIRT1 and ER stress by a mechanism related to increased expression of hypermethylated in cancer 1 (HIC1). Taken together, these data show that cellular vitamin B12 has a strong modulating influence on ER stress in N1E115 dopaminergic cells. The impaired cellular availability in vitamin B12 induces irreversible ER stress by greater acetylation of HSF1 through decreased SIRT1 expression, whereas adding vitamin B12 produces protective effects in cells subjected to ER stress stimulation.

Cell Death and Disease (2013) 4, e553; doi:10.1038/cddis.2013.69; published online 21 March 2013

Subject Category: Neuroscience

Cells are constantly exposed to environmental stresses including the abundance or lack of key nutrients and may respond rapidly by decreasing cellular key protein contents, as well as proliferation rate to ensure their survival. ${ }^{1}$ One of these nutrients is vitamin B12, whose deficiency produces neurodegenerative and cognitive disorders by molecular mechanisms that remain elusive. The dissection of these mechanisms is of great importance, considering the key role of vitamin B12 during perinatal and aging processes when vitamin B12 deficiency is independently associated with abnormal cognitive development, ${ }^{2}$ and with neurodegenerative diseases such as Alzheimer's disease and Parkinson's disease. $^{3-5}$ To impair cellular availability for vitamin B12, we have developed a NIE-115 dopaminergic cell model by anchoring transcobalamin, a high-affinity binding protein of vitamin B12, to endoplasmic reticulum (ER) through its fusion with oleosin. 6,7 The chimeric protein diminishes the bioavailable vitamin B12 destined towards the cytoplasm and the mitochondria. Interestingly, whereas transcobalamin-oleosin (TO) chimera behaves as a very efficient chelator for cobalamin, oleosin-transcobalamin (OT) chimera shows no cobalamin-binding activity. In agreement with the role of vitamin $\mathrm{B} 12$ as a cofactor of methionine synthase, a reduced SAM level is only associated with TO cells; the phenotype of the OT-transfected cells is not different from either the wild-type non-transfected cells or the cells expressing

\footnotetext{
${ }^{1}$ INSERM U954, Nutrition Génétique et Exposition aux Risques Environnementaux, Faculté de Médecine, Université de Lorraine, Vandœuvre les Nancy, France *Corresponding author: J-L Gueant or S-F Battaglia-Hsu, INSERM U954, Nutrition Génétique et Exposition aux Risques Environnementaux, Faculté de Médecine, Université de Lorraine, 9 Avenue de la Foret de Haye, Vandœuvre les Nancy, Cedex 54505, France. Tel: + (33) 0383683292; Fax: + (33) 0383683279; E-mail: jeanlouis.gueant@univ-lorraine.fr or shyue-fang.battaglia@univ-lorraine.fr

${ }^{2}$ These authors contributed equally to this work.

Keywords: SIRT1; HSF1; vitamin B12; ER stress; methylation; acetylation

Abbreviations: TO, transcobalamin-oleosin; OT, oleosin-transcobalamin; B12, vitamin B12, cobalamin; ER, endoplasmic reticulum; TCII, transcobalamin II; SAM, sadenosyl methionine; SAH, s-adenosyl homocysteine; PP2A, protein phosphatase 2A; NGF, nerve growth factor; TACE, tumor necrosis factor (TNF)-converting enzyme; SIR2, silent information regulator 2; SIRT1, sirtuin (silent mating type information regulation 2 homolog) 1; HSF1, heat-shock factor protein 1; BiP, binding immunoglobulin protein; HSP70s, heat-shock protein-70 family proteins; AdoX, adenosine-2', $3^{\prime}$-dialdehyde; IGF-1, insulin growth factor 1; FOXO, forkhead box family proteins; P53, tumor protein 53; GCN2, general control nonrepressed 2; PERK, protein kinase RNA-like endoplasmic reticulum kinase; PKR, double-stranded RNAactivated protein kinase; HRI, heme-regulated elF2 $\alpha$ kinase; CreP, constitutive repressor of elF2 $\alpha$ phosphorylation; GADD34, growth arrest and DNA damage protein 34; PGC-1 $\alpha$, peroxisome proliferator-activated receptor gamma coactivator $1 \alpha$; elF2 $\alpha$, eukaryotic initiation factor $2 \alpha$; P-elF2 $\alpha$, phosphorylated eukaryotic initiation factor $2 \alpha$; RNA, ribonucleic acid; DNA, deoxyribonucleic acid; HSR, heat-shock response

Received 23.8.12; revised 22.12.12; accepted 17.1.13; Edited by A Verkhratsky
} 
transcobalamin alone. ${ }^{6,7}$ The most discernible consequences found in TO cells include reduced proliferation, accelerated differentiation and augmented apoptosis. ${ }^{7,8}$ Reduced proliferation has also been observed in other vitamin B12-deficient non-neuronal cell models, including that created by the downregulation of transcobalamin receptor TCbIR/CD320. ${ }^{9}$ These B12 deficiency-relevant changes are among the signs known to associate with early aging and death, and they bear certain resemblances to those observed in cells under stress. Vitamin B12 deficiency has never been documented to evoke any stress response directly prior to the current study, despite the fact that it can theoretically provoke ER stress indirectly through the accumulation of homocysteine. Exogenous homocysteine was first shown to increase significantly the expression of molecular chaperon GRP78/BiP (binding immunoglobulin protein) (a member of heat-shock protein (HSP) 70 family) and activating transcription factor 4 (ATF4). ${ }^{10}$ Presumably, these upregulations are related to the activation of the ER unfolded protein response (UPR), as ER stress proteins, such as X-box-binding protein (XBP), are activated after the addition of exogenous homocysteine. ${ }^{11-13}$

Sirtuin 1 deacetylase (SIRT1), the closest mammalian homolog of the yeast silent information regulator 2 (SIR2) protein, was originally identified as a transcriptional silencing factor at the silent mating loci, telomeres and ribosomal DNA. ${ }^{14-16}$ Its overexpression was later found to extend the lifespan of yeast ${ }^{17}$ and Caenorhabditis elegans. ${ }^{18}$ Although the exact details of how SIR2 extends the lifespan remain still obscure, its role in maintaining genomic stability and repairing DNA, as well as its involvement in antioxidative stress response and insulin/IGF-I signaling probably are all relevant to the lengthening of lifespans. In mammalian cells, SIRT1 downregulation has further been linked with cell differentiation, aging, senescence and various pathological events such as insulin resistance and severe oxidative stress. ${ }^{19}$ Its broader role as a stress-response protein was first brought to light by the discoveries that it interacts with both tumor protein 53 (p53) and forkhead box family protein 3 (FOXO3), and as a result blocks DNA damages as well as oxidative stress. ${ }^{20,21}$ Facilitated by its association with p53 and FOXO3, SIRT1 deacetylates these protein partners. Whereas SIRT deacetylation renders p53 less active in inducing apoptosis and senescence, the deacetylation of FOXO3 by SIRT1 potentiates its transcriptional activity, leading to the upregulation of genes for cell cycle arrest and DNA damage repair. Another key player of the SIRT1dependent stress response is heat-shock factor 1 (HSF1), whose activation increases the transcription of molecular chaperones such as HSP70 and HSP90. SIRT1 deacetylates HSF1 and potentiates its binding to the heat-shock promoter of the molecular chaperone genes. ${ }^{22}$ Activation of SIRT1 thus participates in protecting cells from stresses related to damaged, misfolded or aggregated proteins. Besides its roles in DNA damage stress, oxidative stress and misfolded protein stress, SIRT1 participates in the stress response consequent to inadequate nutrients uptake. ${ }^{23,24}$ SIRT1 expression is reduced in rodents fed with either diet deficient in methyl donors ${ }^{25}$ or a high-fat/glucose (sucrose) diet. $^{26-29}$ The imbalanced acetylation/methylation of PGC- $1 \alpha$ due to the reduction of SIRT1 expression produced an impaired fatty acid oxidation with myocardium hypertrophy in methyl donor-deficient young rodents. ${ }^{25}$

Taken these data together, we thus asked whether vitamin B12 deficiency induces cellular stress through an altered expression of SIRT1. This article reports that cellular vitamin B12 availability, by controlling SIRT1expression, modulates the severity of ER stress by influencing the extent of HSF1 expression and acetylation in N1E115 dopaminergic cells.

\section{Results}

Impaired cellular availability of B12 induces ER stress. The presence of an important cell stress in B12-deficient TO N1E115 cells was first identified by the increase in level of the ER stress transducers, P-PERK, P-IRE1 $\alpha$ and ATF6 (Figure 1a and Supplementary Figure 1) and the increased phosphorylation of eukaryotic initiation factor $2 \alpha$ (P-elF $2 \alpha)$ in TO versus control OT cells. As the high P-elF $2 \alpha$ level in TO cells could be reversed upon the addition of vitamin B12 and SAM, we suggest this stress response to be vitamin B12and methylation-dependent (Figure 1a and Supplementary Figure 1). As elF2 $\alpha$ phosphorylation on serine 51 is the convergent response to a multiplicity of cellular stresses including those induced by nutritional means, we investigated subsequently the kinases involved in this upregulation. The large increase in P-elF2 $\alpha$ level observed in TO cells was concluded as being mainly related to ER stress, considering the increased expression of PKR-like ER kinase (PERK) (Figure 1a) and the unchanged expression of the other elF2 $\alpha$ kinases, namely double-stranded RNA-activated protein kinase (PKR), general control non-repressed 2 (GCN2) and heme-regulated elF2 $\alpha$ kinase (HRI) (Supplementary Figure 2). As ATF6 activation during ER stress involves its translocation from ER to nucleus via Golgi apparatus, ${ }^{30}$ we examined further the translocation of ATF6 using immunofluorescence approach and found that whereas in control OT cells nuclear ATF6 stain occurred in only $\sim 10 \%$ cells, in TO cells it occurred in $\sim 20 \%$ of cells $(P<0.001)$ (Figure $1 \mathrm{~b})$. These results suggested that the activation of ATF6 indeed occurred after the regulated intra-membranous proteolysis (RIP) taking place in Golgi. ${ }^{31}$

XBP, ATF4 and pro-apoptotic markers are activated by ER stress in TO cells. ATF 4 and XBP, two main immediate downstream effectors of the three stress transducers, as well as two pro-apoptotic proteins, CHOP and caspase 3 , were subsequently investigated in TO and OT cells to evaluate the consequences of the ER stress produced by the impaired cellular availability of B12. ATF4 level was upregulated in TO cells (Figure 2a, upper panel) most likely as a result of integrated stress response related to the increased elF2 $\alpha$ phosphorylation. The ATF4 activation could be reversed only by $B 12$, but not by SAM. IRE1 $\alpha$ splicing of the XBP transcript from $1 U \rightarrow 1 S$ appeared also more important in TO cells (Figure 2a, lower panel), confirming further the activation of ER stress response in TO cells. The higher expression of the pro-apoptotic markers, CHOP and cleaved caspase 3, showed that TO cells were tuned towards irreversible stress and thus resulted in a compromised proliferation marked by 


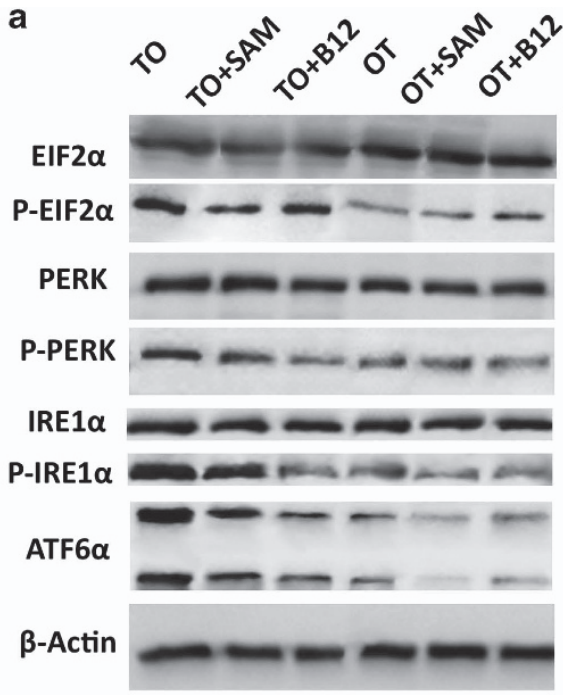

b

TO
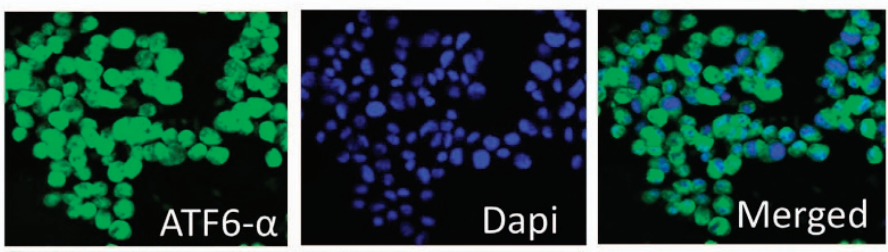

OT
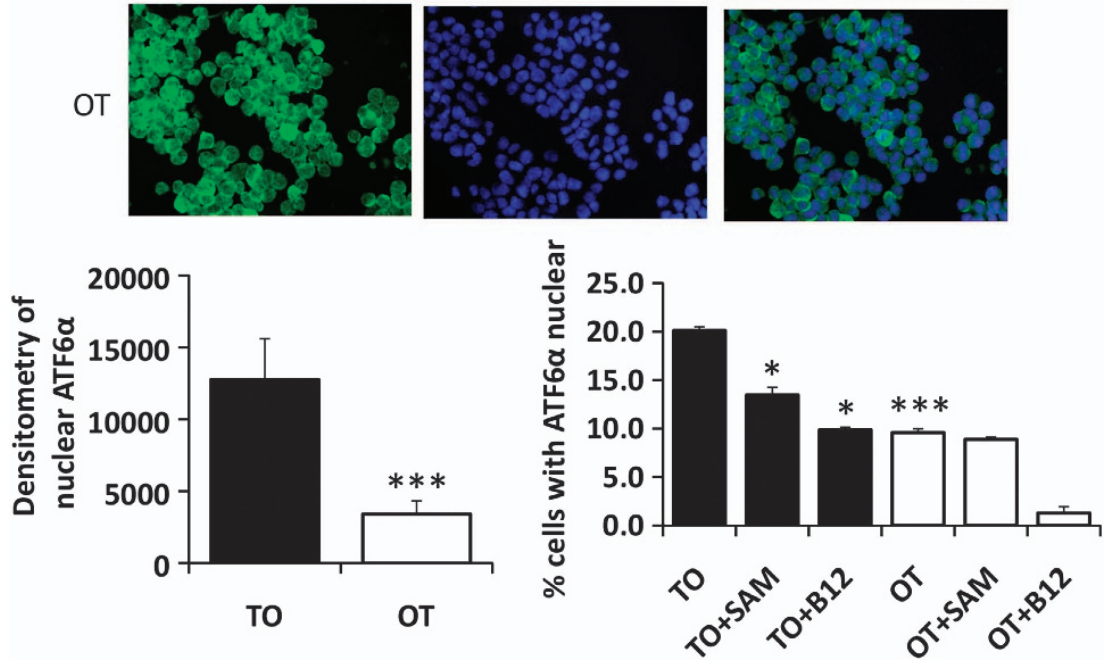

Figure 1 Impaired cellular availability of B12 induces ER stress. (a) Representative western blots of elF-2 $\alpha$, phosphorylated elF-2 $\alpha$ (p-elF-2 $\alpha$ ), PERK, phosphorylated PERK (p-PERK), IRE-1 $\alpha$, phosphorylated IRE-1 $\alpha$ (p-IRE-1 $\alpha$ ), and ATF6 obtained from B12-deficient TO cells and control OT cells before and after treatment with B12 at $20 \mu \mathrm{M}$ and with SAM at $75 \mu \mathrm{M}$, respectively. Densitometry analyses are presented in Supplementary Figure 2; (b) B12-deficient TO and non-deficient OT cells were stained with anti-ATF6 antibody coupled to Alexa 488 (green) and with DAPI (blue). The immunofluorescence density in the nuclei of the two types of cells were compared in more than 300 cells and found to be significantly different at $P<0.0001$. Furthermore, the percentage of cells with nuclear ATF staining was compared in TO versus OT cells before and after B12 and SAM treatment. Before treatment, ATF6 nuclear localization was found in an average of $20 \%$ (TO) versus $10 \%($ OT) cell population (*** $P<0.001$ ); after SAM and B12 treatment, this level reduced to about 13 and $10 \%$ in TO cells, respectively $\left({ }^{\star} P<0.05\right)$.

the decrease in Ki67 (Figure $2 b$ and Supplementary Figure $3 \mathrm{~A}$ ). This maladaptation to stress was consistent with the greatly reduced expression of molecular chaperons including BiP, HSP70, HSP90 and HSP27 in TO versus OT cells (Figure 2c and Supplementary Figure 3B). As reduced molecular chaperon expression could be related to the state of acetylation in HSF1 by SIRT1, we tested subsequently the idea that SIRT1 may be responsible for the ER stress induced by B12 deficiency.
Increased acetylation of HSF1 through decreased SIRT1 expression is responsible for ER stress in TO cells. SIRT1-dependent stress response involves HSF-1, a key stress-activated transcription factor capable of activating genes encoding HSPs. SIRT1 deacetylation of HSF-1 potentiates its transcriptional activity. ${ }^{22}$ Given the evidence that HSPs were significantly reduced in TO cells (Figure 2c and Supplementary Figure 3B), we asked whether the acetylation of HSF1 was associated to SIRT1 expression. 
ATF4

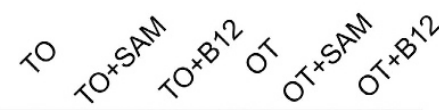

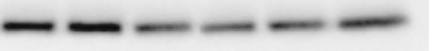

so

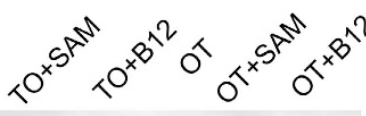

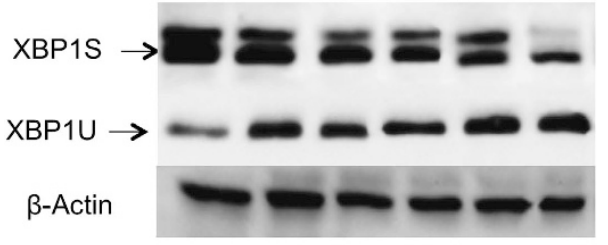

b
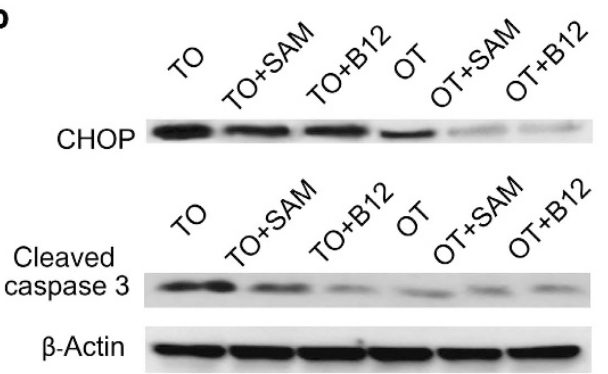

C

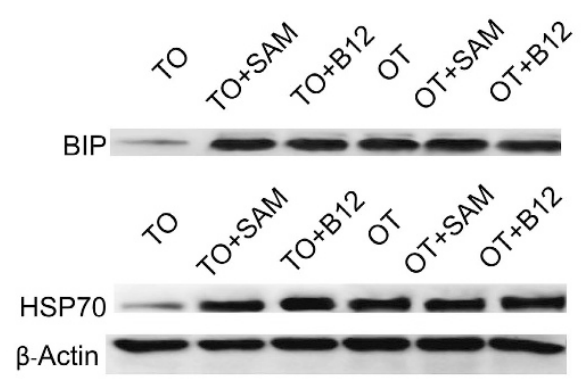

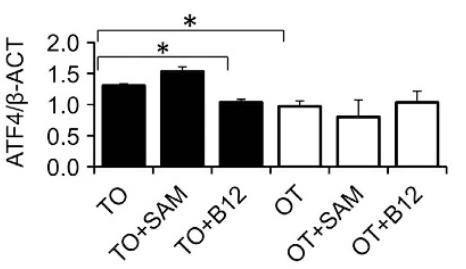
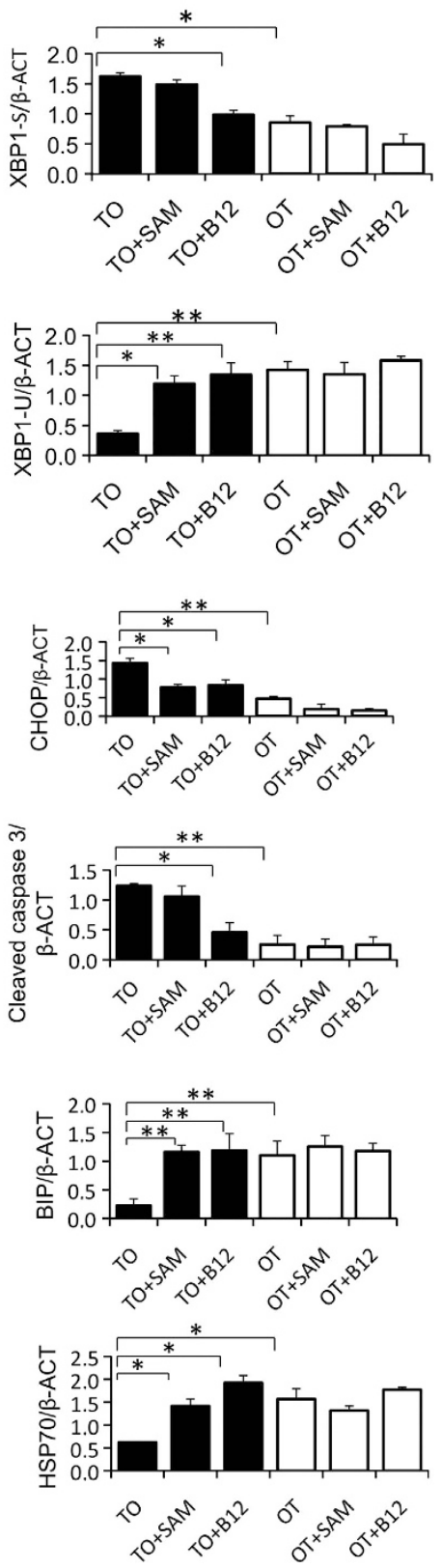

Figure 2 In B12-deficient cells, XBP, ATF4 and apoptosis are activated as results of ER stress. The downstream signaling pathways of ER stress are activated in TO cells. These include increased ATF4 expression and XBP splicing (a), as well as increased expression of CHOP and cleaved caspase 3 (b). The activation of these ER stress markers was related to the reduced level of molecular chaperons such as HSP 70 family members (c). Data were compared by one-way ANOVA with Fisher's test, with $n=8$ in each group, and presented as means \pm S.E. $\left({ }^{*} P<0.05 ;{ }^{* *} P<0.01\right)$

Western blot analysis using anti-acetyl lysine on the immunoprecipitated HSF1 revealed decreased expression and increased acetylation of HSF1 in TO cells (Figure 3a). This higher acetylation of the HSF1 in TO cells also affected its cellular localization (and thus its activity as a transcription factor), moving HSF1 from the nucleus to the cytoplasm (Figure 3b). Consistent with these results, the level of SIRT1 (both the transcript and the protein) was reduced in TO versus OT cells and this reduction was B12-dependent (Figure $4 a, P<0.001$ ). 
a
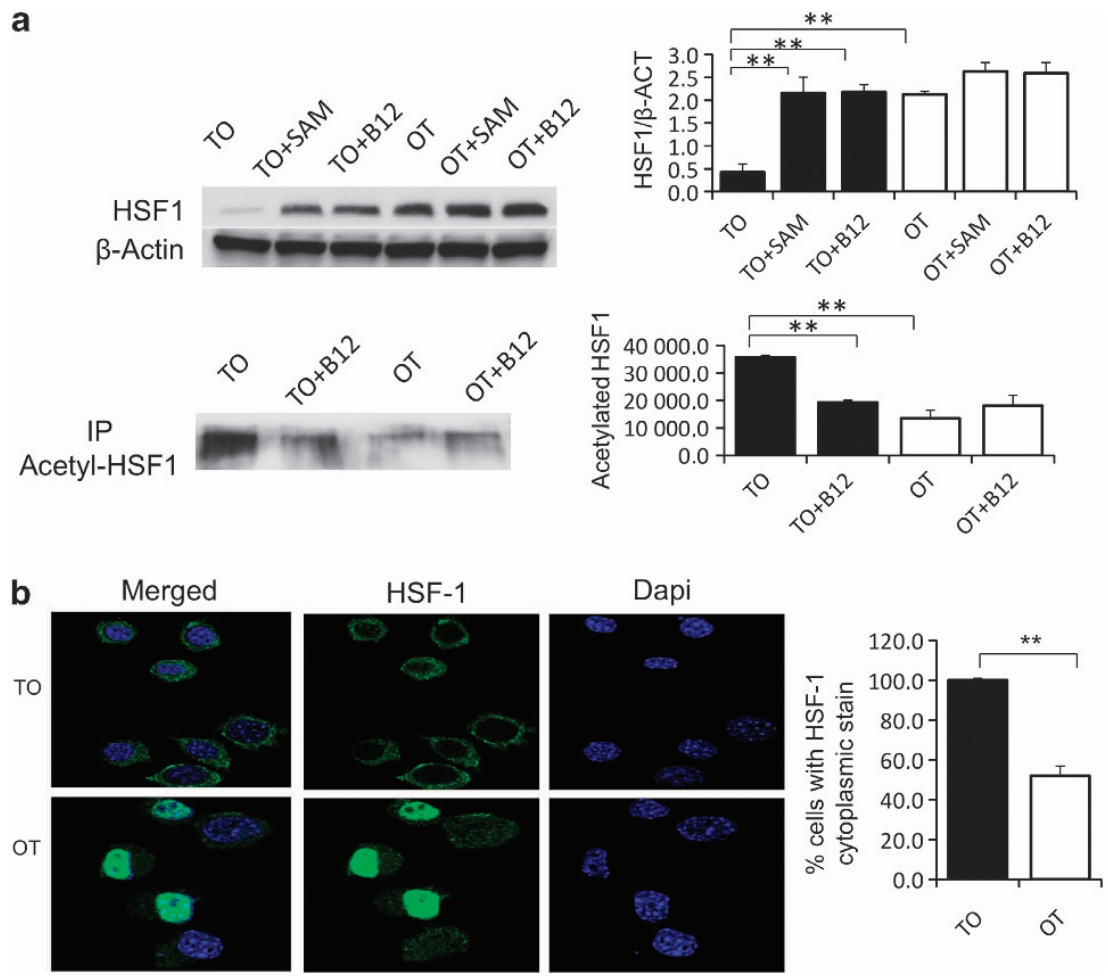

Figure 3 HSF1 expression is decreased in TO cells with impaired cellular availability of B12. In TO cells, the HSF1 protein level is significantly reduced compared with that in control cells $(P<0.01)$. In addition, the HSF1 protein present in TO cells is overwhelmingly acetylated $(P<0.01)(a)$. Immunofluorescence staining of the HSF1 protein (green) in TO and OT cells reveals more TO than OT cells with weak nuclear HSF1 staining $(P<0.0001)(b)$. Data were compared by one-way ANOVA with Fisher's test, with $n=8$ in each group, and presented as means \pm S.E. $\left({ }^{*} P<0.05 ;{ }^{* *} P<0.01\right)$

To confirm the link between SIRT1 and ER stress in these cells, we further investigated the ER stress response in cells treated with known SIRT1 activator and inhibitor. We applied on one hand SRT1720, a SIRT1 activator, to TO cells to restore their diminished SIRT1 activity, and on the other hand EX527, a SIRT1 inhibitor, to OT control cells to decrease their SIRT1 activity. As shown in Figure 4b, boosting SIRT1 activity with SRT1720 in TO cells resulted in increased BiP and decreased ATF4 and CHOP expression, whereas depressing SIRT1 activity by EX527 in OT cells led to reduced BiP and increased ATF4 and CHOP expression. Expression of the two independent siRNA in control OT cells against SIRT1 both reduced the expression of $\mathrm{HSP} 70$ and $\mathrm{BiP}(P<0.01)$, and increased the expression of the ER stress transducers $(P<0.05)$ (Figure 4c). The addition of B12 reduced the expression of ER stress transducers despite the inhibition of SIRT1 expression, suggesting a protective effect of B12 on ER stress (Figure 4c).

SIRT1 was also overexpressed to rescue the ER stress of the TO cells. Transient transfection with the SIRT1 plasmid increased SIRT1 protein level in TO $(P<0.001)$, but not in OT cells $(P>0.05)$; this led to a significant reduction of the ER stress in TO cells, and therefore higher cellular proliferation evidenced by the extensively reduced P-IRE1 $\alpha(P<0.05)$, p-PERK level $(P<0.05)$ and Ki67 $(P<0.05)$. These changes were most likely due to the increased HSPs expression $(P<0.05)$ in TO cells (Supplementary Figures $4 \mathrm{~A}$ and $\mathrm{B})$, consequent to the augmented HSF1 protein level after SIRT1 overexpression.
Taken together, all these data suggest that the ER stress in B12-deficient cells is caused by a decreased SIRT1 expression and a subsequently increased acetylation of HSF1.

Overexpression in TO cells or knockdown of the HSF1 function in OT cells can either rescue or aggravate the B12-associated ER stress. To evaluate further the direct role of HSF1 in B12-associated ER stress, we independently knocked down and overexpressed HSF1 in TO and OT cells. First, siRNA against HSF1 was used to knockdown the HSF1 expression in both cells (Figure $5 \mathrm{a}$ and Supplementary Figures $5 \mathrm{~A}$ and $\mathrm{B}$ ). In TO cells, no effect of this knockdown could be discerned based on either the HSPs' expression or the ER stress markers. This lack-of-effect could be accounted for by the fact that no further reduction in HSF1 protein could be detected in TO cells. On the contrary, in OT cells, the same siRNA effectively knocked down HSF1 expression $(P<0.01)$, causing large increases in ER stress makers $(P<0.05)$, presumably due to the significant consequential decrease of HSPs' expression $(P<0.05)$. Secondly, we overexpressed independently a constitutively active form of HSF1 (Hsf1-act) and a dominant-negative mutant form of HSF1 (Hsf1-inact) in both TO and OT cells via transient transfection (Figure $5 \mathrm{~b}$ and Supplementary Figures 5C-E). In TO cells, Hsf1-act transfection led to a higher HSF1 protein level $(P<0.05)$ and as a result, increased HSPs' expression $(P<0.05)$, and reduced ER stress $(P<0.05)$ and apoptosis $(P<0.05)$ were observed along with an increased cellular proliferation $(P<0.05)$. No effect, 
a

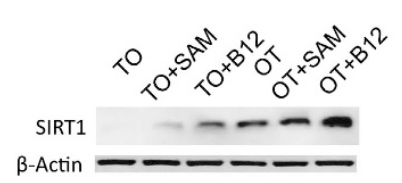

b

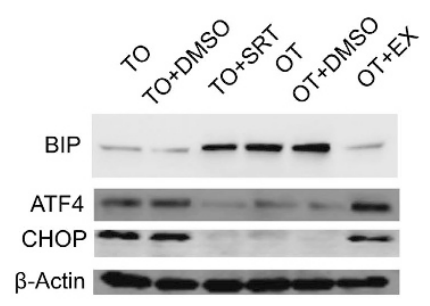

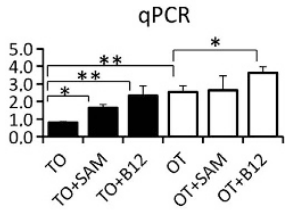

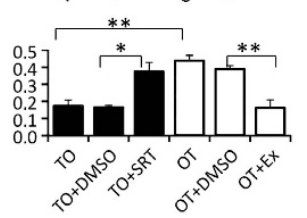

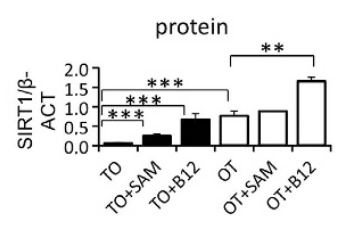
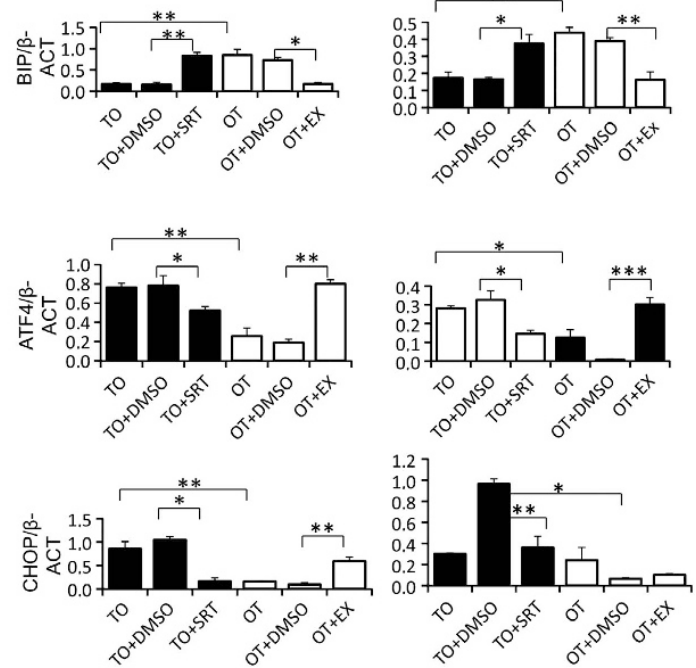

C
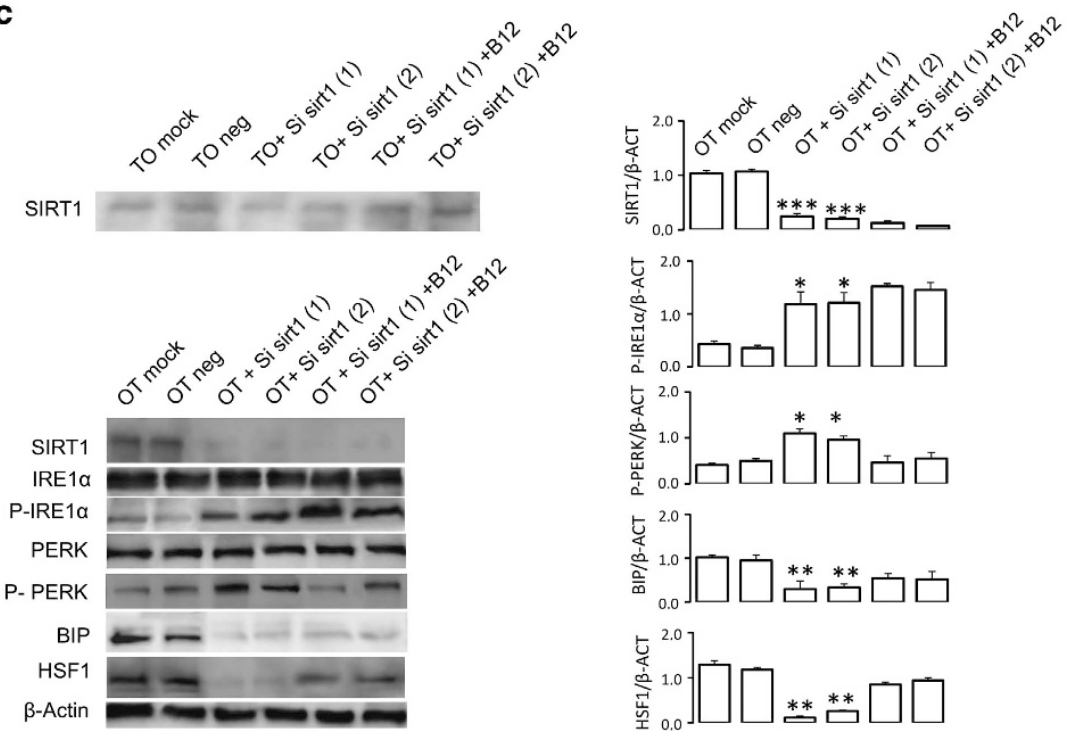

Figure 4 ER stress in B12-deficient cells stems from SIRT1 decreased expression. The levels of SIRT1 protein and transcript are lower in TO than in OT cells, respectively. Supplement with either B12 or SAM significantly increases SIRT1 level in TO cells $(P<0.001)$ (a). Modulation of the activity of SIRT1 via either an activator (SRT1720, denoted as SRT here) in TO cells or an inhibitor (EX527, denoted as EX here) in OT cells alters the expression of ER stress markers: SRT in TO cells increases BiP expression and attenuates ATF4 and CHOP expression $(P<0.05, P<0.01$ and $P<0.01$, respectively) (b); EX in OT cells decreases BiP expression and leads to increased ATF4 and CHOP expression $(P<0.01, P<0.01$ and $P<0.05$, respectively) (b). Reduced SIRT1 expression in control OT cells using two different siRNA against SIRT1 $(P<0.001)$; both leads to decreased HSF1 and BiP expression $(P<0.01$ and $P<0.01)$, as well as increased $p$-IRE $1 \alpha$ and $p$-PERK expression $(P<0.05$ and $P<0.05)(\mathbf{c})$. Data were compared by one-way ANOVA with Fisher's test, with $n=8$ in each group, and presented as means \pm S.D. $\left({ }^{\star} P<0.05 ;{ }^{* *} P<0.01 ;{ }^{* * \star} P<0.001\right)$

however, could be detected when TO cells were transfected with the dominant negative Hsf1-inact construct. In OT cells, inverse effects were observed; no difference in ER stress was detected with the expression of the constitutively active Hsf1-act, whereas adverse effects were noted in OT cells transfected with Hsf1-inact construct. These included the reduction in HSPs' expression, increase in ER stress markers and the corresponding increase in apoptosis and decrease in cellular proliferation. Thirdly, we applied a pharmacological activator, celastrol, to increase the activity of the HSF1 protein and observed consistent results as cells transfected with Hsf1 constructs (Figure 5c and Supplementary Figures $6 \mathrm{~A}$ and $\mathrm{B}$ ). In TO cells, celastrol caused a significant increase in HSF1 protein level $(P<0.05)$. This increase led to lower ER stress (all $P<0.05$ ), lower apoptosis (all $P<0.05$ ) and higher 

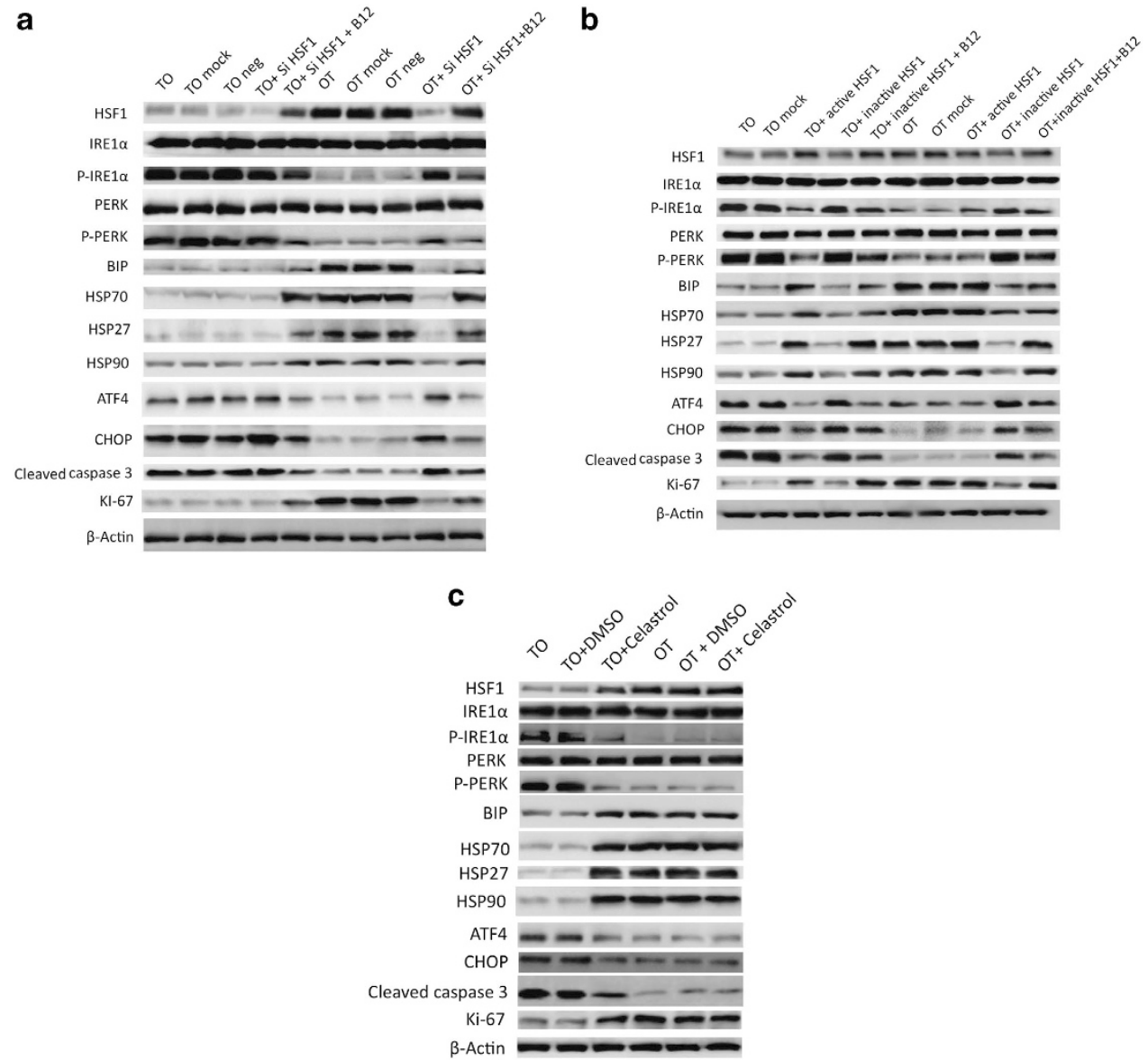

Figure 5 Overexpression in TO cells or knockdown of the HSF1 protein in OT cells can either rescue or aggravate the B12-associated ER stress. (a) Whereas transfecting TO cells with siRNA against HSF1 results in no significant changes to either the ER stress or the apoptosis, the same transfection in OT cells leads to lowered HSPs expressions (all $P<0.05$ ) and consequently higher ER stress and apoptosis (all $P<0.05$ ), as well as lowed proliferation $(P<0.001)$. (b) Transfection with either a constitutively activated Hsf1 (Hsf1-act) or a dominant negative Hsf1 (Hsf1-inactive) construct shows similar results. In TO cells, positive effects are seen with the transfection of the Hsf1-act on HSPs expressions, ER stress reductions, apoptosis and proliferation, whereas no effect can be discerned when Hsf1-inactive construct is transfected into the same cells. In OT cells, adverse effects are seen only when the Hsf1-inactive construct is transfected into the cells and no difference can be detected with the transfection of the Hsf1-act construct. (c) Equally, the positive effects of celastrol, an activator for HSF1, on HSPs expression, ER stress and apoptosis can only be seen in TO cells, but not in OT cells

proliferation (Ki67, $P<0.05)$. Moreover in OT cells, no difference could be found in either HSF1 protein expression or the downstream events including the HSPs' expression, level of ER stress, apoptosis and cellular proliferation.

B12 reversed the activation of ER stress induced by thapsigargin. To evaluate the modulating effect of B12 on ER stress, we investigated its addition to cells subjected to thapsigargin (TG), an ER calcium pump inhibitor, which is a strong stimulator of ER stress. TG induced the activation of ER stress transducers, namely P-IRE and P-PERK, in control non-deficient OT cells, $(P<0.05)$, but not in TO cells (Figures 6a, b and Supplementary Figure 7). Despite so, TG appeared to trigger further apoptosis in TO cells (Figure 6c). TG also reduced the protein expression of HSP70s in both TO and OT cells (Figure $6 \mathrm{~d}$ ), even though their transcription were actually elevated (Supplementary Figure 7). Similar reductions after TG treatment had been reported recently in cultured pancreatic $\beta$ cells and attributed to increased protein degradation by proteasome. ${ }^{32}$ Vitamin $\mathrm{B} 12$ had a remarkable protecting effect against the ER stress induced by TG. The addition of $\mathrm{B} 12$ reversed both the activation of ER stress transducers (Figures $6 a$ and $b$ ) and apoptosis (Figure 6c), and increased the expression of protein chaperons after TG treatment (Figure $6 \mathrm{~d}$ ). These protective effects of B12 were also observed in TO and OT cells treated with EX527, a SIRT1 inhibitor (Figure 7).

The reduced SIRT1 expression is homocysteine-independent and is under the influence of methylationdependent mechanisms. To address here whether homocysteine had a part in the ER stress triggered by the impaired cellular availability of B12, we evaluated the effects of homocysteine itself on SIRT1 expression. SIRT1 expression was increased in N1E115 cells after a relatively long-term homocysteine treatment (6-7 days at $15 \mu \mathrm{M})$ (Figure 8a). This result allowed us to conclude that the low/moderate level of homocysteine produced in TO cells has no significant role in the SIRT1-related ER stress response of the TO cells. In addition, no modification in ER stress markers was 


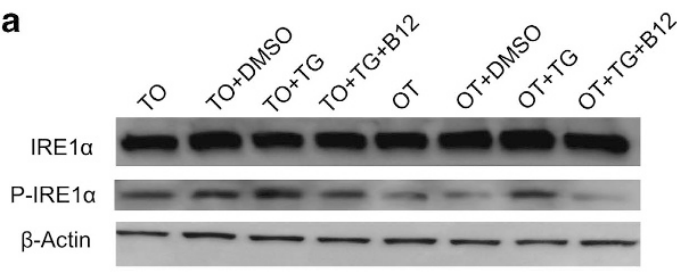

b

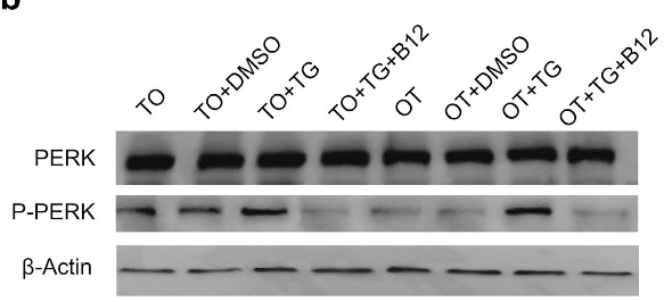

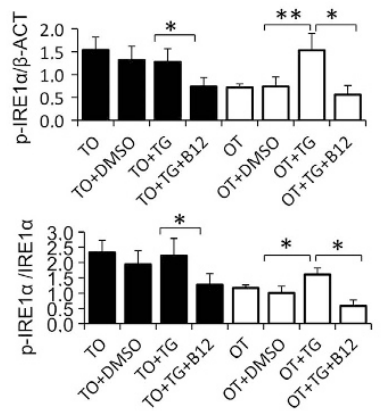

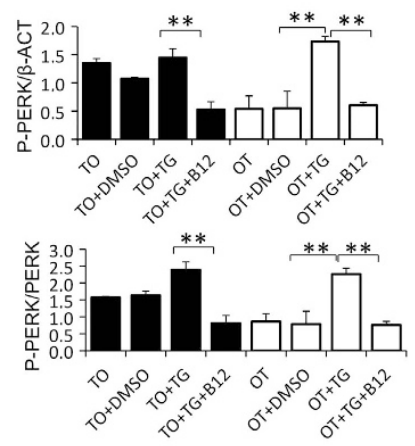

C
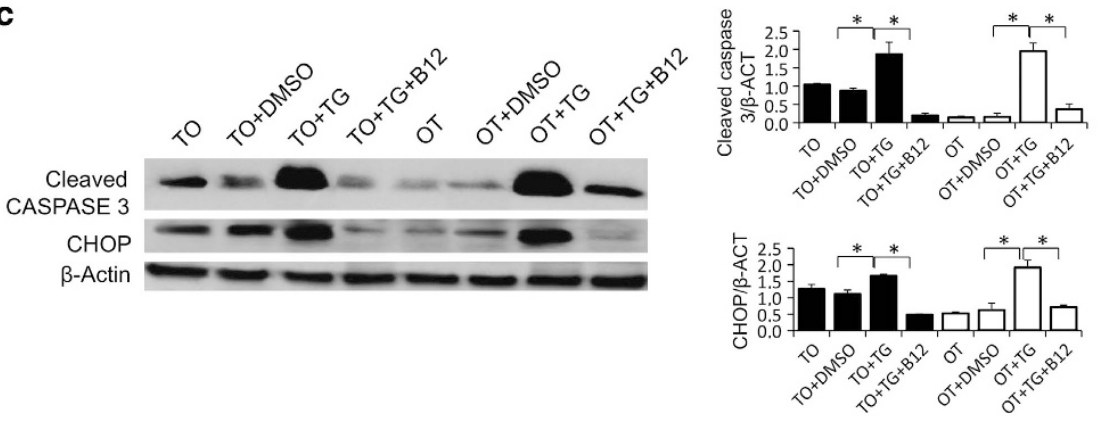

d

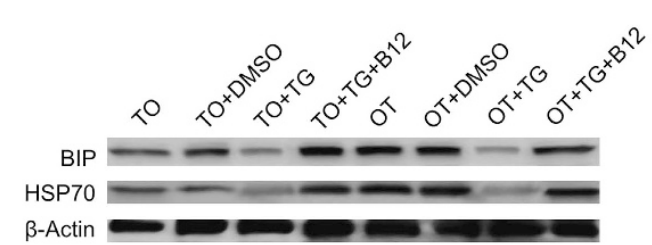

Figure 6 TG elicits further activation on ER stress transducers in N1E115 TO cells and shifts these cells toward apoptosis. P-IRE1 $\alpha$ increases in control OT cells after TG treatment $(P<0.01)$. Addition of $B 12$ in the culture medium reduces this activation in both cell types $(a, P<0.05)$. More significant $P$-PERK activation is observed in control $O T$ versus TO cells after TG treatment, whereas B12 reduces this activation in both cell types $(P<0.01)(b)$. TG at $1 \mu \mathrm{M}$ for $5 \mathrm{~h}$ induces significant increases in CHOP and cleaved caspase 3 expression in both cell types, and B12 reduces these expressions $(P<0.05$ for all comparisons) (c). TG treatment reduces both the expression of BiP and HSP70 in both cell types (d). The same TG treatment induces significantly more BiP and HSP70 expression in TO cells $(P<0.01)$. Data were compared by one-way ANOVA with Fisher's test, with $n=8$ in each group, and presented as means \pm S.E. $\left({ }^{*} P<0.05\right.$ and $\left.{ }^{* *} P<0.01\right)$

observed in presence of methylmalonic acid (MMA) (Supplementary Figures $8 \mathrm{~A}$ and $\mathrm{B}$ ). We also tested the hypothesis that SIRT1 expression is mediated by a methylation-dependent mechanism using adenosine- $2^{\prime}, 3^{\prime}$-dialdehyde (AdoX) as a methyltransferase inhibitor. ${ }^{33}$ AdoX decreased
SIRT1 transcription and translation in control cells, reduced the protein level of HSF1, HSP70, BiP and increased the protein level of ER stress transducers, as well as the transcription level of 'hypermethylated in cancer 1' (HIC1) (Figures $8 \mathrm{~b}$ and $\mathrm{c}$ ). 

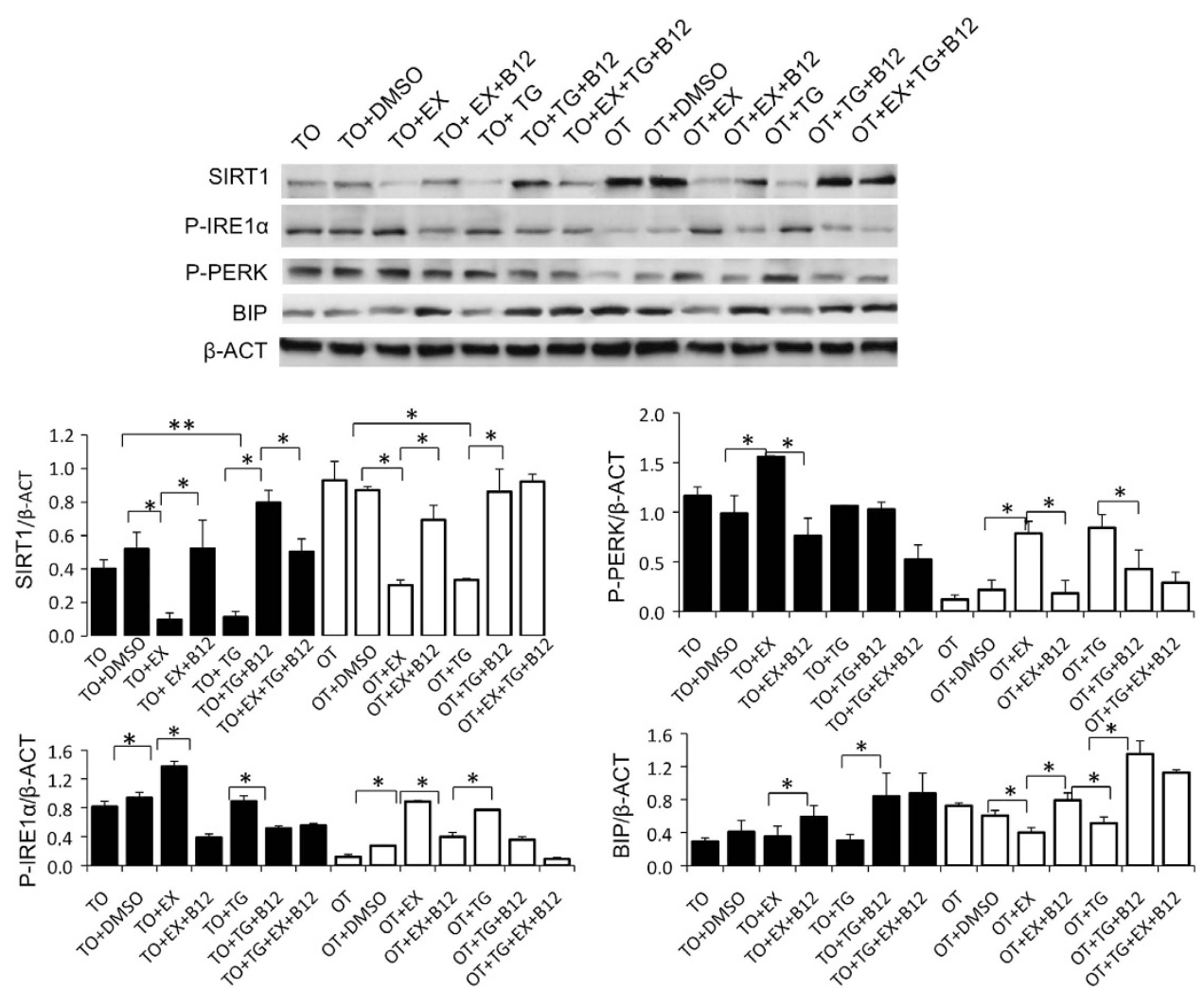

Figure 7 The effect of the activator and inhibitor of SIRT1 on the expression of ER stress markers is modulated by vitamin B12 in TO and OT cells. SIRT1 inhibitor, EX527, reduces the SIRT1 protein expression in both cell types $(P<0.01)$ and B12 supplement reverses its effects on ER stress transducers, including P-PERK $(P<0.05)$ and P-IRE $1 \alpha(P<0.05$ for all comparisons). B12 reverses also the expression of BiP after EX527 treatment in TO and OT cells $(P<0.05$ for both cell types). Data were compared by one-way ANOVA with Fisher's test, with $n=8$ in each group, and presented as means \pm S.E. $\left({ }^{\star} P<0.05\right.$ and $\left.{ }^{* *} P<0.01\right)$

\section{Discussion}

Previous studies in cells have demonstrated that the cellular availability of vitamin $\mathrm{B} 12$ is relevant to cellular proliferation. ${ }^{6-9}$ Evidences here show that ER stress participates in this process. Our data clearly show that impaired cellular availability of vitamin B12 produces this stress through an impaired expression of SIRT1 and a subsequent increased acetylation of HSF1. Indeed, the effect of B12 on ER stress was influenced by the different conditions of activity and expression of SIRT1 and HSF1. Consistently, reduced SIRT1 expression resulted in increased HSF1 acetylation in B12deficient TO cells. Adding either vitamin B12 or SAM to TO cells restored the level of SIRT1 expression. The fact that a reduced SIRT1 expression occurred concurrently with an increased $\mathrm{HIC} 1$ expression in TO cells and that similar scenario to the B12 deficiency (i.e., reduced SIRT1, HSF1 and HSP7Os as well as increased ER stress) can be reproduced in control OT cells using the methylation inhibitor AdoX suggest the involvement of methylation. Indeed, SIRT1 interacts with the BTB/POZ domain of $\mathrm{HIC} 1$ to form a transcriptional repression complex that prevents the transcription of SIRT1 itself $^{34}$. Westerheide et al. ${ }^{22}$ have demonstrated that SIRT1 affects the attenuation phase of heat shock response by deacetylating HSF1, and as a consequence potentiates the binding between HSF1 and heat shock promoter. Consequent to the reduced SIRT1 expression in
TO cells, the increased acetylation of HSF1 accelerates the attenuation of heat shock response and leads to less than optimal amount of molecular chaperon needed for assuring proper cellular growth (Supplementary Figure 5). This in turn triggers the integrated stress response epitomized by the phosphorylation of elF2 $\alpha$ in the B12-deficient TO cells. This increased P-PERK-dependent phosphorylation of elF2 $\alpha$ is under the influence of vitamin B12. It is consistent with the increased expression of ATF4 observed in TO cells and is known to inhibit ER protein translation. ${ }^{35}$ It is worth noting that the total HSF1 protein expression is significantly reduced in the TO cells. Although the exact reason for this decrease is not clear, the drop in SIRT1 protein level may also account for the downregulation of HSF1. ${ }^{36}$ Our own overexpression experiment using SIRT1 constructs (Supplementary Figure 4) certainly supports this idea. Heat shock response in senescent cells is associated to a reduced HSF1 protein level/activity caused by SIRT1 depletion and p53 activation. ${ }^{36}$ HSF1mediated heat shock response is an integral part of the network crucial for the health of the cellular proteome. A dysfunctional heat shock response logically triggers UPR of the ER attributable to the accumulation of misfolded proteins. In TO cells, these stress responses most likely culminate in apoptosis reflected by the increased expression of $\mathrm{CHOP}$ and cleaved caspase 3. Previous studies had established that high doses of homocysteine (ranging from 1 to $10 \mathrm{mM}$ ) could rapidly induce ER stress response with the upregulation of molecular 

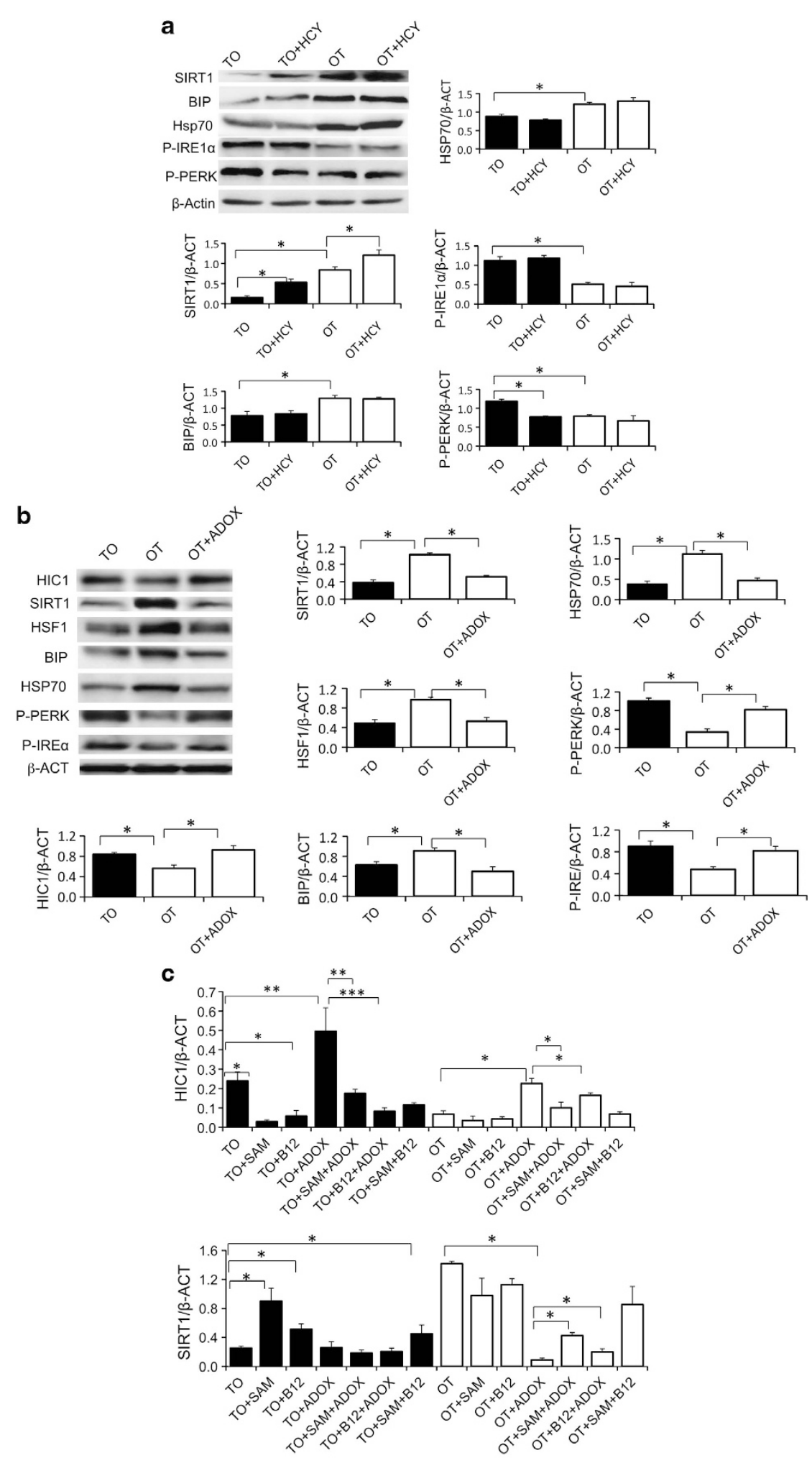

Figure 8 The reduced SIRT1 expression is homocysteine-independent and methylation-dependent. (a) SIRT1 expression increases after homocysteine treatment in both TO and OT cells $(P<0.05$ for both), whereas P-PERK activation is reduced in TO cells $(P<0.05)$. (b) AdoX treatment in OT cells increases the protein expression of HIC1 $(P<0.05)$ and decreases the expression of SIRT1, HSF1 and BiP. It increases the expression of the two ER stress transducers, $P$-IRE $1 \alpha$ and $P$-PERK $(P<0.05$ in both cell types). (c) Influence of SAM, vitamin B12 and the methyltransferase inhibitor AdoX on the relative abundance of SIRT1 and HIC1 transcripts in TO and OT cells. AdoX increases significantly the relative abundance of HIC1 transcript in TO cells $(P<0.001)$, which can be partially reversed by the addition of either SAM $(P<0.01)$ or B12 $(P<0.001)$. These same changes occur also in the control OT cells (upper panel). Inversely, AdoX treatment decreases the relative abundance of SIRT1 transcript in control OT cells only, and the addition of either SAM or B12 reverse this reduction in SIRT1 transcript $(P<0.05$ for both comparisons) (lower panel). Data were compared by one-way ANOVA)with Fisher's test, with $n=8$ in each group, and presented as means \pm S.E. $\left({ }^{\star} P<0.05 ;{ }^{* \star} P<0.01\right.$ and $\left.{ }^{* \star *} P<0.001\right)$ 
chaperons such as BiP. ${ }^{11,12,37}$ In contrast, using a homocysteine application at a concentration consistent with the metabolic changes in TO cells, we observed an increased SIRT1 protein expression in both control and B12-deficient cells. The SIRT1 reduction in TO cells was thus not related to homocysteine accumulation. We also ruled out the participation of the MMA, a neurotoxin itself, in ER stress, as no modification in ER stress markers was observed (Supplementary Figure 8).

One important implication drawn from our results is the modulating effect of vitamin B12 on ER stress. Our study here used TG as an activating agent for ER stress. In TO cells, TG treatment exerted no further activation on the ER stress transducers; instead, it swayed the cells towards apoptosis. In OT cells, TG activated significant ER stress and apoptosis. B12 supplement in both cell types restored the level of SIRT1; it thus reduced the activation of the ER stress transducers and apoptosis via increased expression of HSP70s. Interestingly, the beneficial effect of the supplemental B12 on ER stress was still present after decreasing either the expression or the activity of SIRT1. Thus, a reduction in bioavailable B12 sensitizes cells to downstream assaults, and supplementation in $\mathrm{B} 12$ can reduce pre-existent ER stress.

These beneficial effects of B12 supplement lend themselves to investigations on possible neuroprotective effects and on the consequences of B12 deficiency in ER stressrelated neurodegenerative disorders such as Parkinson's disease. ${ }^{38,35}$ Parkinson's disease is the second most common neurodegenerative disease related to aging. The environmental factors and the pathomechanisms that lead to Parkinson's disease are still unclear. ${ }^{38}$ Recently, we have shown that in rat's substantia nigra an impaired metabolism of vitamin B12 in dopaminergic neurons can lead to apoptosis and account for the Parkinson-like phenotype in TO targettransfected rats. ${ }^{8}$ Our results here indicate that the apoptosis of the TO-transfected dopaminergic cells is consequent to the mal-adapted ER stress response and are consistent with previous findings, suggesting the involvement of SIRT1 and ER stress for the loss of dopaminergic neurons. ${ }^{39-44}$ The impact of vitamin B12-cellular deficiency on apoptosis of dopaminergic cells through the activation of ER stress thus highlights the importance of prevention against vitamin B12 insufficiency prior to the incidence of diseases. Finally, our results may help to explain the association of vitamin B12 with Parkinson's disease in clinical studies. ${ }^{45}$ Levodopa treatment of Parkinson's disease patients increases the consumption of SAM in the O-methylation of Levodopa catalyzed by catecholO-methyltransferase (COMT). Consequently, in patients undergoing Levodopa therapy, the cellular deficiency in SAM could exacerbate vitamin B12 deficiency, and thus either escalate an existing ER stress or initiating an ER stress not present previously. ${ }^{46}$

In conclusion, we have presented evidence indicating that a decreased cellular availability of B12 leads to ER stress activation mediated by decreased SIRT1expression. This reduction in turn leads to both lower HSF1 expression and HSF1 hyperacetylation. These result in the precarious reduction of the molecular chaperons needed for a functional proteome in normal cellular growth (Supplementary Figure 9). This molecular mechanism could contribute to the neurodegenerative effects of B12 deficiency in dopaminergic cells.
Additionally, we have shown that B12 supplementation protects cells from the downward spiral of the ER stressassociated apoptosis in cells treated with TG. Accordingly, we suggest that adequate status of cellular B12 shall have beneficial/protective effect and thus can safeguard cells against any downstream attacks; on the other hand, in B12deficient cells, UPR once activated will be shifted from adaptive towards apoptotic maladaptive end point.

\section{Materials and methods}

Cell culture and siRNA/plasmid transfections. N1E115 culture protocol was as described previously. ${ }^{6,7}$ For stably transfected TO and OT cells, G418 at $1 \mathrm{mg} / \mathrm{ml}$ was included in the culture medium. The B12-binding capacity of the stably transfected cells were verified using radioactive $\mathrm{C}^{57}-\mathrm{CNB} 12^{6}$ before and right after the experimental manipulations to ensure that TO cells remained B12-deficient and OT cells remained as control. Hydroxycobalamin, SAM, AdoX, celastrol and SIRT1 inhibitor, EX527, were purchased from Sigma (Lyon, France). SIRT1 activator SRT1720 was obtained from Euromedex (Strasbourg, France). In cases where cells were treated either with hydroxycobalamin $(20 \mu \mathrm{M})$ or SAM $(75 \mu \mathrm{M})$, an incubation period of 5-7 days was applied. For TG, cells were treated for $5 \mathrm{~h}$ at $1 \mu \mathrm{M}$. For AdoX, we treated the cells only for $24 \mathrm{~h}$ at a concentration of $20 \mu \mathrm{M}$, as the typical $48 \mathrm{~h}$ treatment led to cell death in more than $90 \%$ of the population. For SRT1720, the cells were treated for $8 \mathrm{~h}$ at $1 \mu \mathrm{M}$ and for EX527, the cells were treated at $5 \mu \mathrm{M}$ for $7 \mathrm{~h}$. The homocysteine treatment included an application of homocystine for 6 consecutive days at a final concentration of $15 \mu \mathrm{M}$ in the cell culture medium. For cells treated with celastrol, a concentration of $3 \mu \mathrm{M}$ was applied in cultured medium during a $24 \mathrm{~h}$ period. For the MMA treatment, we incubated the cells in MMA (Sigma, Lyon, France) containing media for 7 days at concentrations of 1,5 and $25 \mu \mathrm{M}$.

In experiments where SIRT1 siRNA transfections were applied, two siRNAs obtained from Life Technologies (Saint Aubin, France) were used to confirm the specificity of the interference targeted to SIRT1. The siRNA sequences are (sense strand indicated): siSIRT1-1: $5^{\prime}$-GCUUGGAAGAUGAUACGGATT-3', siSIRT1-2: $5^{\prime}$-GAAAACUACUUCGAAAUUATT-3', and a scrambled siRNA was used as the transfection control and designated as si non-targeting $5^{\prime}$-UUGAUGUGUUUAGUCGCUA-3' (Applied Biosystems, Saint Aubin, France s96764 and s96765; $10 \mathrm{nM}$ final concentration). In experiments where HSF-1 and control siRNAs were used, the siRNAs were obtained from both Life technologies and Fisher Scientific (Illkirch, France). The siRNA sequences are (sense strand indicated): siHSF1-1: $5^{\prime}$ AGCAAAAAGUUGUCAACAATT-3'. The siRNA duplexes were transfected with lipofectamine 2000 (Invitrogen, Saint Aubin, France) $24 \mathrm{~h}$ after plating the N1E115 cells in $100 \mathrm{~mm}$ dishes at a density of $6 \times 10^{5}$ cells per dish. Two days post transfection, N1E115 cells were harvested for protein extraction. The treatment with SAM or B12 was applied $48-72 \mathrm{~h}$ prior to transfection.

In the overexpression experiments: SIRT1 and HSF1 plasmids are obtained from Addgene (Cambridge, MA, USA), and the pcDNA3-based plasmids of the active HSF1 and the inactive HSF1 plasmids were gifts from Dr. N Harrison (Columbia University, New York City, NY, USA). Hsf1-act has a long deletion of amino acids 203-315 in the regulatory domain of HSF1, whereas the dominant-negative mutant form of HSF1 has a deletion of amino acids 453-523 located in the transcription activation domain. ${ }^{47}$

Western blot. To prepare total cell lysate, live cells were lysed directly with a solution containing sodium phosphate anhydrous dibasic, potassium dihydrogen phosphate, $150 \mathrm{mM} \mathrm{NaCl}, 1 \%$ Nonidet P40, $0.5 \%$ sodium deoxycholate, sodium dodecyl sulfate and Complete Protease Inhibitors (Roche, Boulogne-Billancourt, France) after washing twice with ice-cold $1 \mathrm{X}$ PBS. Lysates were then subjected to a thermal shock followed by a centrifugation at 12000 r.p.m. for $30 \mathrm{~min}$. The protein concentration of the supernatant was determined using BCA Protein Assay kit (Pierce, Brebieres, France) and BSA as standard protein. In general, $40 \mu \mathrm{g}$ of the total protein was loaded per lane for SDS-PAGE. Depending on the molecular mass of the protein, the stacking and the separating gel contained 4 and $6-12 \%$ of acrylamide, respectively. Proteins were electrotransferred onto PVDF membranes (Millipore, Molsheim, France) in $25 \mathrm{mM}$ Tris buffer containing $192 \mathrm{mM}$ glycine and $20 \%$ (vol/vol) methanol. The membranes were then blocked either with $5 \%$ non-fat milk or $5 \%$ BSA for $1 \mathrm{~h}$ at room temperature. The PVDF membrane was then incubated overnight with various primary antibodies (SIRT1, HSF1, BiP, IRE- 
1alpha, PERK, phospho-PERK, cleaved caspase 3, elF2 alpha, phospho-elF2 alpha, CHOP, acetyl-lysine, GCN2, HSP90, HSP 27 (Cell Signaling, Saint Quentin en Yvelines, France), HRI, PKR, ATF-6 alpha (Santa Cruz, Nanterre, France), phospho-IRE-1alpha (Novus Biologicals, Montluçon, France), XBP (Biodesign, Memphis, TN, USA), HSP70 (Stress marq, Nanterre, France), ATF4 (Abnova, Le Perray en Yvelines, France), Ki-67 (Abcam, Paris, France) and $\beta$-actin (US biological, Strasbourg, France). Appropriate secondary antibodies conjugated to HRP were used for detection with ECL or ECL PLUS reagent (Amersham, Velizy-Villacoublay, France).

Immunoprecipitation. Cell lysates were prepared as described previously in the western blot section above. Protein immunoprecipitation was done using an immunoprecipitation kit (Roche) following the manufacturer's recommendation. Briefly, an aliquot of cell lysate containing exactly $800 \mu \mathrm{g}$ of total protein was incubated with $50 \mu \mathrm{l} \mathrm{G}$-sepharose beads at $4^{\circ} \mathrm{C}$ overnight. Then, $5 \mu \mathrm{l}$ of antiHSF1 (Cell Signaling) were incubated with the supernatant at $4{ }^{\circ} \mathrm{C}$ overnight. After washing the beads several times, the mixture was centrifuged at $12000 \times g$ for $20 \mathrm{~s}$. The pellet was resuspended in $100 \mu \mathrm{l}$ laemmli buffer. For repeated run, these 100- $\mu$ l aliquots were loaded per lane for SDS-PAGE gel electrophoresis followed by an immunoblotting against a primary antibody antiacetyl lysine (Cell Signaling).

Immunoflorescence. Neuroblastoma cells were grown on slides for $48 \mathrm{~h}$. Then, they were fixed with paraformaldehyde/saccharose for $10 \mathrm{~min}$ at $4{ }^{\circ} \mathrm{C}$ and blocked with BSA for $1 \mathrm{~h}$. Cells were incubated with various primary antibodies: HSF1, caspase3, Ki67, ATF6 $\alpha$ (Imagenex, Port Coquitlam, BC, Canada) overnight in a humid chamber at $4{ }^{\circ} \mathrm{C}$ under a gentle agitation. Slides were washed four times in BSA/PBST for 5 min then incubated with the secondary antibody for $1 \mathrm{~h}$ at room temperature under a gentle agitation. Detection of the nucleus was done with the nuclear fluorescent dye 4, 6-diamidino-2-phenylindole (DAPI) $(0.43 \mu \mathrm{g} / \mathrm{ml}$ in PBS; Sigma, Lyon, France). Finally, slides were washed four times in PBS and mounted using a minimal volume of faramount mounting medium (DAKO, Carpinteria, CA, USA). The immunostained cells were imaged using Nikon C2 equipped with three laser lines (405, 488 and 543). The images were obtained with $\times 60$ oil immersion lens.

LCMSMS determination of homocysteine and MMA. For the determination of Hcy and MMA, TO and OT cells (treated or not with SAM or B12) were seeded in 6-well plates. After $48 \mathrm{~h}$ of incubation, cells were scraped and centrifuged in the cell-medium suspension for $5 \mathrm{~min}$ at $15000 \times \mathrm{g}$ r.p.m. Subsequently, we aspirated the medium and used it for further LCMSMS analysis. Homocysteine and MMA were determined in cell media by LC-MS/MS using an Acquity UPLC (Waters, St. Quentin en Yvelines, France) and a triple quadripole mass spectrometer 4000 QTRAP (AB sciex, Courtaboeuf, France) as described. ${ }^{7}$ Quantification was made using calibration curves with correction against internal standard peak area.

Real time PCR. Total RNA was extracted using Rneasy plus Mini Kit (Qiagen), including DNase digestion. Reverse transcription was done by using the iScript cDNA Synthesis System (Bio-Rad, Marnes-la-Coquette, France) Quantitect Reverse Transcription kit (Qiagen, Paris, France). Quantitative PCR was performed using SYBR Green I Master Mix buffer (Applied Biosystems, Saint Aubin, France), Quantitect SYBR Green PCR kit from Qiagen and reactions were run on an iCycler (Bio-Rad, Marnes-la-Coquette, France) using a three-step standard protocol: activation of HotStartTaq DNA polymerase at $95^{\circ} \mathrm{C} / 15 \mathrm{~min}$; PCR was performed in 40 cycles (one cycle $=$ denaturation at $95^{\circ} \mathrm{C} / 10 \mathrm{~s}$, annealing $56-57^{\circ} \mathrm{C} / 15 \mathrm{~s}$, extension at $72{ }^{\circ} \mathrm{C} / 10 \mathrm{~s}$ ). Either RPS29 or actin was used as an internal standard, and differences in expression were calculated using the following formula:

$(1+$ efficiency (gene to study $))^{\mathrm{Ct} \text { standard }-\mathrm{Ct} \text { sample }}$

$(1+$ efficiency (reference gene) $){ }^{\text {Ct standard }-\mathrm{Ct} \text { sample }}$

The oligonucleotides used are as follows:

SIRT1: forward: 5'-GACGATGACAGAACGTCACAC-3'; reverse: 5'-CGAG GATCGGTGCCAATCA-3'; CHOP: forward: $5^{\prime}$-GTCCCTAGCTTGGCTGACA GA-3'; reverse: $5^{\prime}$-TGGAGAGCGAGGGCTTTG-3'; BiP: forward: $5^{\prime}$-ACTTGG GGACCACCTATTCCT-3'; reverse: 5'-CGAGGATCGGTGCCAATCA-3'; ATF4: forward: 5'-ATGGCGCTCTTCACGAAATC-3'; reverse: 5'-ACTGGTCGAAGGGG TCATCAA-3'.

HSP70: forward: $5^{\prime}$-GCGTGGGGGTATTCCAACAT-3'; reverse: $5^{\prime}$-TGAGAC GCTCGGTGTCAGT-3'.
HIC1: forward: 5'-GGCCATTCGAGGCAGCTAC-3'; reverse: 5'-AGGTTTAGCA GGTTGTCATGC-3'.

Statistics. Data were analyzed with Stata 12.0 software (StataCorp, College Station, TX, USA) and reported as means \pm S.E. Data were compared by one-way analysis of variance (ANOVA) with Fisher's test. A $P$-value $<0.05$ was considered to indicate statistical significance. Results are denoted by asterisks in figures $\left({ }^{\star} P<0.05 ;{ }^{* \star} P<0.01\right.$ and $\left.{ }^{* \star *} P<0.001\right)$.

\section{Conflict of Interest}

The authors declare no conflict of interest.

Acknowledgements. This study was supported by fundings from the Region Lorraine and the French National Agency for Research (ANR Nutrivigène). We would like to thank Dr. N Harrison of the Columbia University (New York City, NY, USA) for the HSF-1 active and HSF1-inactive plasmids and advices for their transfection, and Dr. DJ Thiele of the Duke University (Durham, NC, USA) for the suggestion of using celastrol as the pharmacological activator of HSF1.

\section{Author contributions}

SB and JLG designed the study, interpreted the data and wrote the paper. RG participated in designing the study, interpreted the data, and participated in the preparation and redaction of the paper. RG, SP, EJ, SL, GG and CM performed the metabolic, cellular and molecular experiments. SB and JLG coordinated the whole study and JLG was the director of the Nutrivigene ANR project. All authors discussed the results and commented on the manuscript.

1. Spriggs $K A$, Bushell M, Willis AE. Translational regulation of gene expression during conditions of cell stress. Mol Cell 2010; 40: 228-237.

2. Bhate V, Deshpande $S$, Bhat D, Joshi N, Ladkat R, Watve $S$ et al. Vitamin B12 status of pregnant Indian women and cognitive function in their 9-year-old children. Food Nutr Bull 2008; 29: 249-254.

3. Garrod MG, Green R, Allen LH, Mungas DM, Jagust WJ, Haan MN et al. Fraction of total plasma vitamin B12 bound to transcobalamin correlates with cognitive function in elderly Latinos with depressive symptoms. Clin Chem 2008; 54: 1210-1217.

4. Hooshmand B, Solomon A, Kåreholt I, Leiviskä J, Rusanen M, Ahtiluoto S et al. Homocysteine and holotranscobalamin and the risk of Alzheimer disease: a longitudinal study. Neurology 2010; 75: 1408-1414.

5. McCaddon A. Homocysteine and cognition-a historical perspective. J Alzheimers Dis 2006; 9: 361-380.

6. Pons L, Battaglia-Hsu SF, Orozco-Barrios CE, Ortiou S, Chery C, Alberto JM et al. Anchoring secreted proteins in endoplasmic reticulum by plant oleosin: the example of vitamin B12 cellular sequestration by transcobalamin. PloS one 2009; 4: e6325.

7. Battaglia-Hsu SF, Akchiche N, Noel N, Alberto JM, Jeannesson E, Daval JL et al. Vitamin $B 12$ deficiency reduces proliferation and promotes differentiation of neuroblastoma cells and upregulates PP2A, proNGF and TACE. Proc Natl Acad Sci USA 2009; 16: 21930-21935.

8. Orozco-Barrios CE, Battaglia-Hsu SF, Arango-Rodriguez ML, Ayala-Davila J, Chery C, Alberto JM et al. Vitamin B12-impaired metabolism produces apoptosis and Parkinson phenotype in rats expressing the transcobalamin-oleosin chimera in substantia nigra. PloS One 2009; 4: e8268.

9. Lai SC, Nakayama Y, Sequeira JM, Quadros EV. Down-regulation of transcobalamin receptor TCbIR/CD320 by siRNA inhibits cobalamin uptake and proliferation of cells in culture. Exp Cell Res 2011; 317: 1603-1607.

10. Kokame K, Kato H, Miyata T. Homocysteine-respondent genes in vascular endothelial cells identified by differential display analysis. GRP78/BiP and novel genes. J Biol Chem 1996; 271: 29659-29665.

11. Althausen S, Paschen W. Homocysteine-induced changes in mRNA levels of genes coding for cytoplasmic- and endoplasmic reticulum-resident stress proteins in neuronal cell cultures. Brain Res Mol Brain Res 2000; 84: 32-40.

12. Kokame K, Agarwala KL, Kato H, Miyata T. Herp, a new ubiquitin-like membrane protein induced by endoplasmic reticulum stress. J Biol Chem 2000; 275: 32846-32853.

13. Outinen PA, Sood SK, Liaw PC, Sarge KD, Maeda N, Hirsh J et al. Characterization of the stress-inducing effects of homocysteine. Biochem $J$ 1998; 332: 213-221.

14. Brachmann CB, Sherman JM, Devine SE, Cameron EE, Pillus L, Boeke JD. The SIR2 gene family, conserved from bacteria to humans, functions in silencing, cell cycle progression, and chromosome stability. Genes Dev 1995; 9: 2888-2902.

15. Ivy JM, Klar AJ, Hicks JB. Cloning and characterization of four SIR genes of Saccharomyces cerevisiae. Mol Cell Biol 1986; 6: 688-702.

16. Smith JS, Boeke JD. An unusual form of transcriptional silencing in yeast ribosomal DNA. Genes Dev 1997; 11: 241-254. 
17. Kaeberlein M, McVey M, Guarente L. The SIR2/3/4 complex and SIR2 alone promote longevity in Saccharomyces cerevisiae by two different mechanisms. Genes Dev 1999; 13 2570-2580.

18. Tissenbaum HA, Guarente L. Increased dosage of a sir-2 gene extends lifespan in Caenorhabditis elegans. Nature 2001; 410: 227-230.

19. Kwon HS, Ott M. The ups and downs of SIRT1. Trends Biochem Sci 2008; 33 517-525.

20. Brunet A, Sweeney LB, Sturgill JF, Chua KF, Greer PL, Lin Y. Stress-dependent regulation of FOXO transcription factors by the SIRT1 deacetylase. Science 2004; 303: 2011-2015.

21. Luo J, Nikolaev AY, Imai S, Chen D, Su F, Shiloh A et al. Negative control of p53 by Sir2alpha promotes cell survival under stress. Cell 2001; 107: 137-148.

22. Westerheide SD, Anckar J, Stevens SM Jr., Sistonen L, Morimoto RI. Stress-inducible regulation of heat shock factor 1 by the deacetylase SIRT1. Science 2009; 323 1063-1066.

23. Grimm AA, Brace CS, Wang T, Stormo GD, Imai S. A nutrient-sensitive interaction between Sirt1 and HNF-1alpha regulates Crp expression. Aging cell 2011; 10 305-317.

24. Strum JC, Johnson JH, Ward J, Xie H, Feild J, Hester A et al. MicroRNA 132 regulates nutritional stress-induced chemokine production through repression of SirT1. Mol Endocrinol 2009; 23: 1876-1884.

25. Garcia Moreno M, Gueant-Rodriguez RM, Pooya S, Brachet P, Alberto JM, Jeannesson E et al. Methyl donor deficiency induces cardiomyopathy through altered methylation acetylation of PGC-1alpha by PRMT1 and SIRT1. J Pathol 2011; 225: 324-335.

26. Chen YR, Fang SR, Fu YC, Zhou XH, Xu MY, Xu WC. Calorie restriction on insulin resistance and expression of SIRT1 and SIRT4 in rats. Biochem Cell Biol 2010; 88: 715-722.

27. Deng $X Q$, Chen LL, Li NX. The expression of SIRT1 in nonalcoholic fatty liver disease induced by high-fat diet in rats. Liver Int 2007; 27: 708-715.

28. Heyward FD, Walton RG, Carle MS, Coleman MA, Garvey WT, Sweatt JD. Adult mice maintained on a high-fat diet exhibit object location memory deficits and reduced hippocampal SIRT1 gene expression. Neurobiol Learn Mem 2012; 98: 25-32.

29. Tang $Y, X u$ J, Qu W, Peng X, Xin P, Yang X et al. Resveratrol reduces vascular cell senescence through attenuation of oxidative stress by SIRT1/NADPH oxidase-dependent mechanisms. J Nutr Biochem 2012; 23: 1410-1416.

30. Chen X, Shen J, Prywes R. The luminal domain of ATF6 senses endoplasmic reticulum (ER) stress and causes translocation of ATF6 from the ER to the Golgi. J Biol Chem 2002; 277: 13045-13052.

31. Shen J, Prywes R. ER stress signaling by regulated proteolysis of ATF6. Methods 2005; 35: 382-389.

32. Rosengren V, Johansson H, Lehtio J, Fransson L, Sjoholm A, Ortsater H. Thapsigargin down-regulates protein levels of GRP78/BiP in INS-1E cells. J Cell Biochem 2012; 113 1635-1644

33. Dolzhanskaya N, Merz G, Denman RB. Alternative splicing modulates protein arginine methyltransferase-dependent methylation of fragile $\mathrm{X}$ syndrome mental retardation protein. Biochemistry 2006; 45: 10385-10393.
34. Chen WY, Wang DH, Yen RC, Luo J, Gu W, Baylin SB. Tumor suppressor HIC1 directly regulates SIRT1 to modulate p53-dependent DNA-damage responses. Cell 2005; 123 : 437-448.

35. Matus S, Glimcher LH, Hetz C. Protein folding stress in neurodegenerative diseases: a glimpse into the ER. Curr Opin Cell Biol 2011; 23: 239-252.

36. Kim G, Meriin AB, Gabai VL, Christians E, Benjamin I, Wilson A et al. The heat shock transcription factor Hsf1 is downregulated in DNA damage-associated senescence, contributing to the maintenance of senescence phenotype. Aging cell 2012; 11: 617-627.

37. Werstuck GH, Lentz SR, Dayal S, Hossain GS, Sood SK, Shi YY et al. Homocysteineinduced endoplasmic reticulum stress causes dysregulation of the cholesterol and triglyceride biosynthetic pathways. J Clin Invest 2001; 107: 1263-1273.

38. Huber K, Superti-Furga G. After the grape rush: sirtuins as epigenetic drug targets in neurodegenerative disorders. Bioorg Med Chem 2011; 19: 3616-3624.

39. Outeiro TF, Kontopoulos E, Altmann SM, Kufareva I, Strathearn KE, Amore AM et al. Sirtuin 2 inhibitors rescue alpha-synuclein-mediated toxicity in models of Parkinson's disease. Science 2007; 317: 516

40. Holtz WA, O'Malley KL. Parkinsonian mimetics induce aspects of unfolded protein response in death of dopaminergic neurons. J Biol Chem 2003; 278: 19367-19377.

41. Ryu EJ, Harding HP, Angelastro JM, Vitolo OV, Ron D, Greene LA. Endoplasmic reticulum stress and the unfolded protein response in cellular models of Parkinson's disease. J Neurosci 2002; 22: 10690-10698.

42. Silva RM, Ries V, Oo TF, Yarygina O, Jackson-Lewis V, Ryu EJ et al. CHOP/GADD153 is a mediator of apoptotic death in substantia nigra dopamine neurons in an in vivo neurotoxin model of Parkinsonism. J Neurochem 2005; 95: 974-986.

43. Sado M, Yamasaki Y, Iwanaga T, Onaka Y, Ibuki T, Nishihara S et al. Protective effect against Parkinson's disease-related insultsthrough the activation of XBP1. Brain Res 2009; 1257: 16-24.

44. Egawa N, Yamamoto K, Inoue H, Hikawa R, Nishi K, Mori K et al. The endoplasmic reticulum stress sensor. ATF6 (alpha), protects against neurotoxin-induced dopaminergic neuronal death. J Biol Chem 2010; 286: 7947-7957.

45. De Lau LM, Koudstaal PJ, Witteman JC, Hofman A, Breteler MM. Dietary folate, vitamin B12, and vitamin B6 and the risk of Parkinson disease. Neurology 2006; 67: 315-318.

46. Miller JW, Shukitt-Hale B, Villalobos-Molina R, Nadeau MR, Selhub J, Joseph JA. Effect of L-dopa and the catechol-O-methyltransferase inhibitor Ro 41-0960 on sulphur amino acid metabolites in rats. Clin Neuropharmacol 1997; 20: 55-66.

47. Zuo J, Rungger D, Voellmy R. Multiple layers of regulation of human heat shock transcription factor 1. Mol Cell Biol 1995; 15: 4319-4330. published by Nature Publishing Group. This work is licensed under a Creative Commons Attribution-NonCommercialNoDerivs 3.0 Unported License. To view a copy of this license, visit http://creativecommons.org/licenses/by-nc-nd/3.0/

Supplementary Information accompanies this paper on Cell Death and Disease website (http://www.nature.com/cddis) 